Article

\title{
Investigation on Morphology and Mechanical Properties of Rod Units in Lattice Structures Fabricated by Selective Laser Melting
}

\author{
Chenchen Jing ${ }^{1, \dagger}{ }^{\dagger}$, Yanyan Zhu ${ }^{1, \dagger}{ }^{,}$Jie Wang ${ }^{2}$, Feifan Wang ${ }^{2}$, Jiping $\mathrm{Lu}^{1}$ and Changmeng Liu ${ }^{1, *}$ \\ 1 School of Mechanical Engineering, Beijing Institute of Technology, Beijing 100081, China; \\ jingchenchen@live.com (C.J.); zhyy2913@bit.edu.cn (Y.Z.); jipinglu@bit.edu.cn (J.L.) \\ 2 China Academy of Launch Vehicle Technology, Beijing Institute of Astronautical Systems Engineering, \\ Beijing 100076, China; ruifangwang0@163.com (J.W.); wangifw@hotmail.com (F.W.) \\ * Correspondence: liuchangmeng@bit.edu.cn; Tel.: +86-10-6891-5097 \\ + These authors contributed equally to this work.
}

check for

updates

Citation: Jing, C.; Zhu, Y.; Wang, J.; Wang, F.; Lu, J.; Liu, C. Investigation on Morphology and Mechanical Properties of Rod Units in Lattice Structures Fabricated by Selective Laser Melting. Materials 2021, 14, 3994. https://doi.org/10.3390/ ma14143994

Academic Editors: Konda Gokuldoss Prashanth and Zhi Wang

Received: 22 June 2021

Accepted: 12 July 2021

Published: 16 July 2021

Publisher's Note: MDPI stays neutral with regard to jurisdictional claims in published maps and institutional affiliations.

Copyright: (c) 2021 by the authors. Licensee MDPI, Basel, Switzerland. This article is an open access article distributed under the terms and conditions of the Creative Commons Attribution (CC BY) license (https:/ / creativecommons.org/licenses/by/ $4.0 /)$.

\begin{abstract}
Selective laser melting (SLM) fabrication of lattice structures has attracted considerable interest due to its many immanent advantages, such as high specific strength. A wide variety of lattice structures have been designed and fabricated. However, as a vital prerequisite for design optimization, a clear relation between the process constraint of SLM and the apparent properties of the fabricated lattice structure has received much less attention. Therefore, this work systematically investigates the characterization and preformation of rod units, which are the basic components of lattice structures, so as to evaluate the SLM manufacturability of lattice structures. A series of rod units with different inclination angles and diameters were fabricated by SLM. Their morphology and mechanical properties were measured by scanning electron microscope observation and a tensile test, respectively. The inclination angle was found to have significant effects on profile error and little effect on mechanical properties. The higher the inclination angle, the larger the profile error. The characteristic diameter had no significant correlation with profile errors and mechanical properties. Based on systematic studies, a formula is proposed to evaluate the cross-sectional area of the fabricated rod units and further estimate their load capacity. This has important implications for optimizing the design of lattice structures fabricated by SLM.
\end{abstract}

Keywords: lattice structures; selective laser melting; Ti-6Al-4V; morphology; mechanical properties

\section{Introduction}

In a wide variety of engineering applications, such as in the aerospace, military, automotive, and medical industries, the weight of parts has significant impacts on both functional performance and usage cost [1-4]. As a typical light weight structure, lattice structures continue to receive considerable interest, as they not only provide good mechanical properties (such as exceptional load bearing efficiency and customizable stiffness), but also possess some intriguing functionalities such as energy absorption, acoustic and elastic wave manipulation, etc. [5-10]. Traditional manufacturing methods of three-dimensional lattice structures include investment casting [11], deformation forming [12], woven/nonwoven metal textiles [13], etc. [14,15]. These methods are complex, costly, have low material utilization efficiency [16], and it is difficult to fabricate very complicated lattice structures. This is where additive manufacturing, also known as 3D printing, comes into play. Additive manufacturing is a technique that fabricates a part layer by layer to form, theoretically, any complex geometries [17]. It provides unprecedented design freedom for fabricating lattice structures and creates much less waste [15]. Selective laser melting (SLM) is one of the most widely used additive manufacturing techniques $[18,19]$. The process of SLM fuses the powder selectively by laser power, layer by layer, according to the slicing of the parts. The powder, fully melted by laser power, will combine with the previous layer and form a dense part [20-23]. This method proposes an idea to fabricate complex lattice structures [24]. As 
for now, significant efforts have been made to use SLM to fabricate lattice structures. For example, Arabnejad et al. [25] proposed two high-strength stretch-dominated cell topologies, and fabricated high-strength porous biomaterials using SLM. Yan et al. designed a new cell type called the gyroid cellular lattice structure [5] and investigated its manufacturability and performance fabricated by SLM [26]. Al-Saedi et al. [27] fabricated a functionally graded lattice structure by SLM, which has a higher energy absorption capacity than a uniform lattice structure.

On the other hand, SLM also has its own processing constraints. When one designs the lattice structure, such processing constraints must be carefully taken into account. This is the vital prerequisite for the design optimization of lattice structures fabricated by SLM. For example, SLM requires a support structure to achieve the required build geometry (for example, fabricating the cantilever structure). This support will be removed after manufacturing. The lattice structure is composed of a large number of cantilever rod units, and support cannot be added since it is inconvenient to remove and will greatly increase surface roughness [28]. This implies that not all build inclinations are permitted in lattice structures. The influence of the angle between the rod and the build direction on the lattice structure is negatively impacted by the principles of the SLM method. In addition, when one designs or predicts the properties of the lattice structure, the same material properties are generally used for all the rod elements in the lattice structure. However, it is well-known that SLM process can compromise the quality of some rod units. A layer-bylayer build-up process makes the parts become anisotropic, which leads to heterogenous mechanical properties in different directions [29-31]. If a clear relation between the process constraint of SLM and the apparent properties of the fabricated lattice structure is not built, one cannot achieve the integrated structure-functionality-fabrication design.

Although a few reports have been presented on this subject, the discussions, especially for mechanical properties, are generally based on the analysis of the whole lattice structure. The complex anisotropic properties of the structure make it difficult to isolate the individual relative contribution of each main unit rod on the overall mechanical response. For example, Leary et al. [32] discussed the manufactural feature size and roughness of structure elements in several lattice structures, such as body centered cubic (BCC), face centered cubic (FCC), body centered cubic with vertical structures (BCCZ), etc. They presented the failure mechanisms and energy absorption characteristics of these lattice structures. Kadirgama et al. [33] investigated Young's modulus, surface roughness, and yield stress of lattice structures which involved four processing parameters (strut size, struct shape, unit cell, and porosity). They found that porosity has a significant influence on both Young's modulus and compressive strength.

Different from these previous works, this work focuses on the unit rod of the lattice structure. It is therefore hoped that the studies will help us to evaluate the separate maneuverability and typical properties of the unit rod, and guide the optimal design of lattice structures. Ti-6Al-4V is chosen due to its wide application. Multiple sets of Ti-6Al$4 \mathrm{~V}$ rod unit structure samples were designed and manufactured by SLM using different inclination angles and diameters. One group did not have support, in order to observe the forming performance of the rod units. The other group uses partial support to test the mechanical properties of the rod. The inclination angle and feature diameter represent the two main features during the design of the rod unit of lattice structures. Therefore, their coupling effects are investigated. The quality and the mechanical response of the fabricated samples are discussed. The error fit formula and the cross-sectional area calculation are presented to estimate the load capacity of the rod unit. The result can serve as a reference for future lattice structure designing.

\section{Materials and Methods}

\subsection{Sample Design}

In this research, two kinds of rod unit structures were designed. One group of the samples was a pure rod unit referred to as 'RA', which was used to study the coupled effect 
of the build direction and the rod diameter on the forming quality of the rod. This group of samples had 49 sets of setups consisting of different combinations of the inclination angle $\theta$ $\left(0-90^{\circ}\right.$, in $15^{\circ}$ increments $)$ and diameter $\mathrm{D}(0.50-2.00 \mathrm{~mm}$, in increments of $0.25 \mathrm{~mm})$. The definition of the inclination angle $\theta$ is marked in Figure 1a. The height of the specimens was $40.82 \mathrm{~mm}$, and the distance between the vertical rods was $10 \mathrm{~mm}$. The corresponding CAD models of RA samples are shown in Figure 2a. The other group was designed for mechanical testing. They are referred to as 'RB' consisting of a rod sandwiched by two plates, as shown in Figure 1b. The rod length was $14 \mathrm{~mm}$, the plate was $10 \mathrm{~mm}$ in length, $8 \mathrm{~mm}$ in width, and the thickness of the plate was the same as the rod diameter. The horizontal rod was $4 \mathrm{~mm}$ higher than the substrate. As in the Table 1 list, the 35 sets tensile specimens were set. The rod diameter $\mathrm{D}$ was set from 1.00 to $2.00 \mathrm{~mm}$ with a $0.25 \mathrm{~mm}$ increase, and the inclination angle was set 0 degree to $90^{\circ}$ with a $15^{\circ}$ increase (as illustrated in Figure 1b). This set number was lower than that of group 1, because some unmanufacturable rods were excluded. The CAD models of the tensile specimens are shown in Figure 3a. The tensile specimens were cut by electrical discharge machining after being manufactured completely.
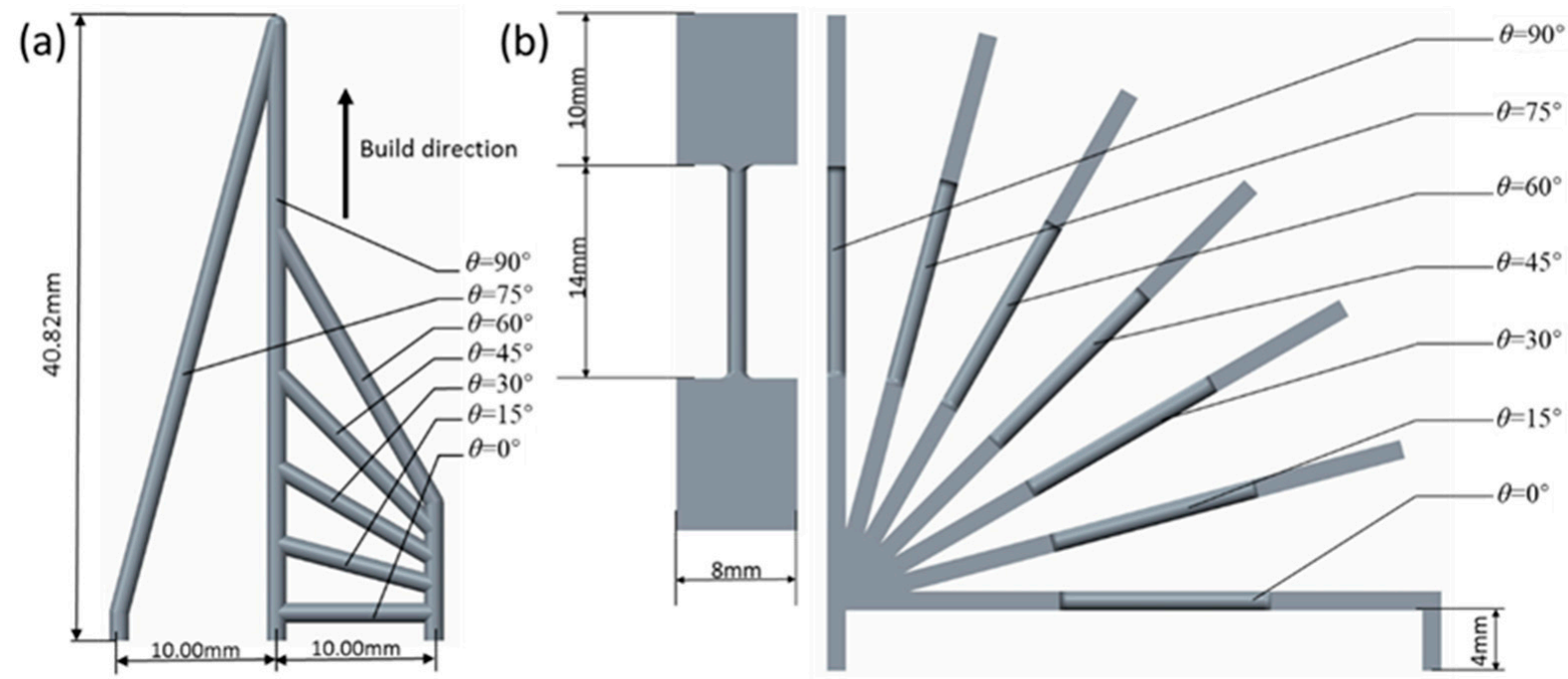

(c)

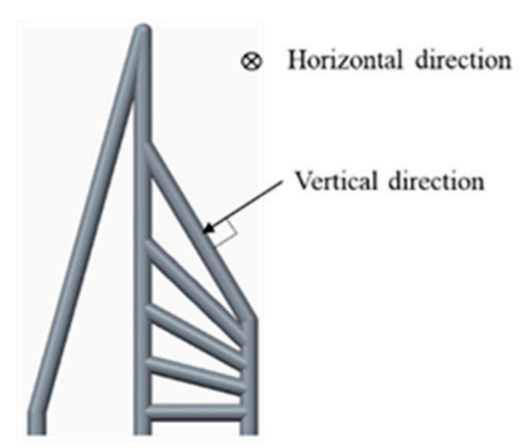

Figure 1. Detail of the sample structure: (a) RA sample used for SEM observing; (b) RB sample used for tensile test; and (c) the view of horizontal direction and vertical direction. 

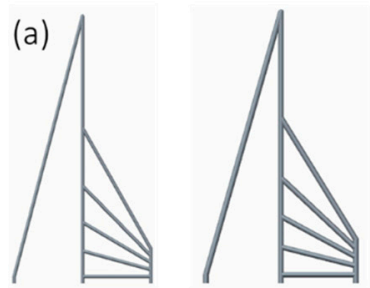

(b)

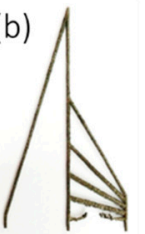

$\mathrm{D}=0.50 \mathrm{~mm}$

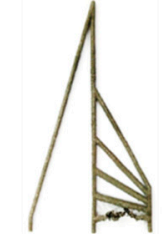

$\mathrm{D}=0.75 \mathrm{~mm}$
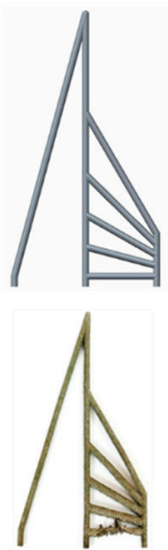

$\mathrm{D}=1.00 \mathrm{~mm}$
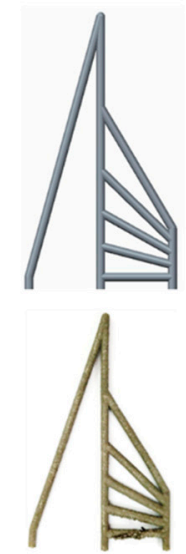

$\mathrm{D}=1.25 \mathrm{~mm}$
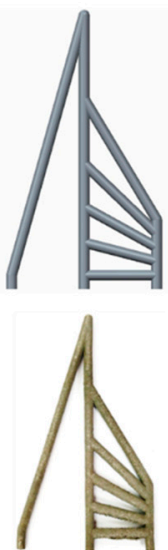

$\mathrm{D}=1.50 \mathrm{~mm}$
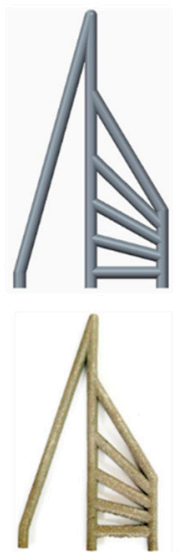

$\mathrm{D}=1.75 \mathrm{~mm}$
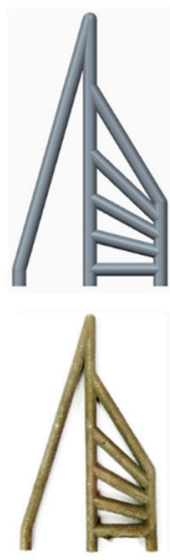

$\mathrm{D}=2.00 \mathrm{~mm}$

Figure 2. RA sample: (a) the CAD model of RA sample for rod diameter of $0.50-2.00 \mathrm{~mm}$ in increments of $0.25 \mathrm{~mm}$ and (b) RA Sample manufactured by SLM.

Table 1. The design parameter of the sample.

\begin{tabular}{cccccccc}
\hline \multirow{2}{*}{$\begin{array}{c}\text { Inclination Angle } \\
\boldsymbol{\theta}\left({ }^{\circ}\right)\end{array}$} & \multicolumn{7}{c}{ Design Diameter (D/mm) } \\
\cline { 2 - 7 } & \multicolumn{2}{c}{ RA Sample } & \multicolumn{5}{c}{ RA \& RB Sample } \\
\hline $\mathbf{0}$ & 0.50 & 0.75 & 1.00 & 1.25 & 1.50 & 1.75 & 2.00 \\
$\mathbf{1 5}$ & 0.50 & 0.75 & 1.00 & 1.25 & 1.50 & 1.75 & 2.00 \\
$\mathbf{3 0}$ & 0.50 & 0.75 & 1.00 & 1.25 & 1.50 & 1.75 & 2.00 \\
$\mathbf{4 5}$ & 0.50 & 0.75 & 1.00 & 1.25 & 1.50 & 1.75 & 2.00 \\
$\mathbf{6 0}$ & 0.50 & 0.75 & 1.00 & 1.25 & 1.50 & 1.75 & 2.00 \\
$\mathbf{7 5}$ & 0.50 & 0.75 & 1.00 & 1.25 & 1.50 & 1.75 & 2.00 \\
$\mathbf{9 0}$ & 0.50 & 0.75 & 1.00 & 1.25 & 1.50 & 1.75 & 2.00 \\
\hline
\end{tabular}

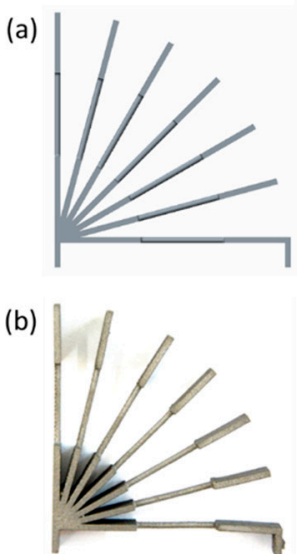

$\mathrm{D}=1.00 \mathrm{~mm}$
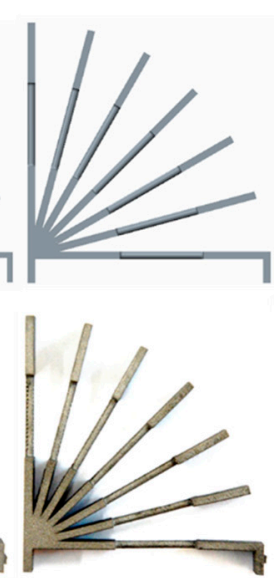

$\mathrm{D}=1.25 \mathrm{~mm}$
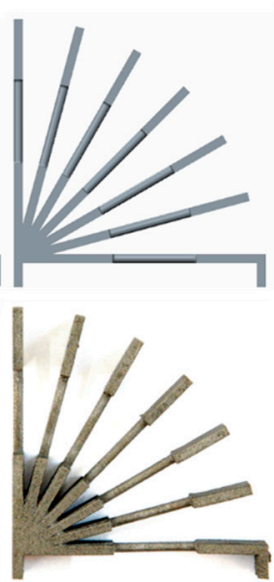

$\mathrm{D}=1.50 \mathrm{~mm}$
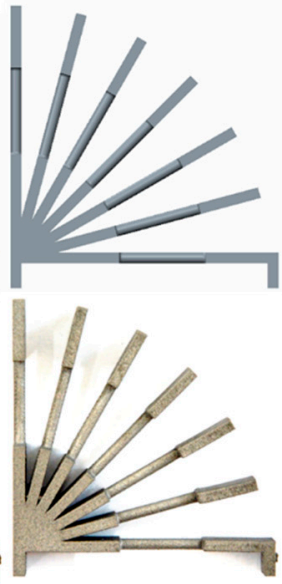

$\mathrm{D}=1.75 \mathrm{~mm}$
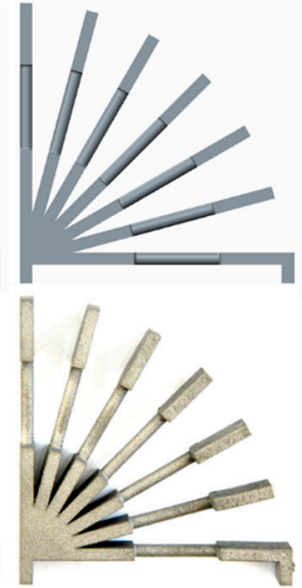

$\mathrm{D}=2.00 \mathrm{~mm}$

Figure 3. RB sample: (a) the CAD model of RB sample for rod diameter of 1.00-2.00 mm in increments of $0.25 \mathrm{~mm}$ and (b) the RB Sample manufactured by SLM.

\subsection{Sample Manufacturing}

Titanium (Ti) alloys have high specific strength and great creep and corrosion resistance [34]. They are widely used in the aerospace field, military field, biomaterial field, etc. $[30,35,36]$. Therefore, Ti-6Al-4V was chosen and fabricated. SLM manufacturing was 
performed using EOSINT M 280 (EOS GmbH, Munich, Germany). The powder was provided by EOS $\mathrm{GmbH}$, and the averaged powder diameter was $36 \mu \mathrm{m}$. The optimal fabrication process parameters for Ti-6Al-4V were chosen as shown in Table 2. Different from printing RA samples without any support, the RB samples exerted the necessary support for the cases of small inclination angle.

Table 2. Processing parameters for the SLM-fabricated Ti-6Al-4V.

\begin{tabular}{cc}
\hline Deposition Parameters & Value \\
\hline Laser power & $260 \mathrm{~W}$ \\
Laser spot size & $80 \mu \mathrm{m}$ \\
Layer thickness & $30 \mu \mathrm{m}$ \\
Scanning speed & $1200 \mathrm{~mm} / \mathrm{s}$ \\
Hatch distance & $40 \mu \mathrm{m}$ \\
\hline
\end{tabular}

\subsection{Macrostructure Observation and Tensile Tests}

Once the manufacturing of the samples had been finished, the diameter of the rod units in the RA sample was measured using SEM. The morphologies of the rod units were studied from the horizontal, vertical, and cross-section directions, respectively, as indicated in Figure 1c. The rod was cut with electrical discharge machining for easy visualization. To prevent the adhesion of powder and other impurities on the observed results, the samples were repeatedly cleaned before observation. Ten random points were measured in each sample, and their average values were used.

The RB samples were cut into individual tensile specimens by electrical discharge machining. Tensile tests were carried on INSTRON 5966 (Instron, Boston, MA, USA). Three samples were used in each group. The tensile tests were conducted according to ASTME-E8/E8M-15a [37].

\section{Results \& Discussion}

\subsection{Macrostructure Observation of RA Samples}

To investigate the coupled effect of inclination angle and design diameter on the quality and morphology of rod units, RA samples without support were designed and fabricated. The manufactured RA samples are shown in Figure 2b. Since no support was applied, the rod element in the horizontal direction could not be formed when the rod was thin $(0.50-1.00 \mathrm{~mm})$. When the diameter increased, the horizontal rod element was gradually stabilized. With the increase of inclination angle, the rod element was more stable and the surface roughness was smaller.

In order to observe the morphology of the sample clearly, Figure 4 shows the SEM images of the rod elements. It reflects the change of the morphology due to inclination angle. From left to right, the inclination angle changed from 90 to $0^{\circ}$, while the diameter $D$ was kept as $1.00 \mathrm{~mm}$. Note that the building direction of SLM is from right to left, and from bottom to top. Figure $4 \mathrm{a}$ is a photograph taken from the horizontal direction (longitudinal profile of the rod as shown in Figure 1c; Figure 4b is a photograph taken from a vertical direction (lateral profile of the rod) with the displayed surface as an upper surface; and Figure 4c is taken from the cross section of the rod. These three directions can well describe the morphology of the sample and reveal the influence of inclination angle on morphology. It can be seen clearly that with the decrease of the inclination angle, the longitudinal dimension gradually increased, and the lateral size only changed a little. When the inclination angle was greater than $45^{\circ}$, the shape of the cross section was close to a circle. When the inclination was smaller than $45^{\circ}$, the top of the cross section was kept circular while the bottom was a conical shape. In addition, the taper increased with the decrease of inclination. 


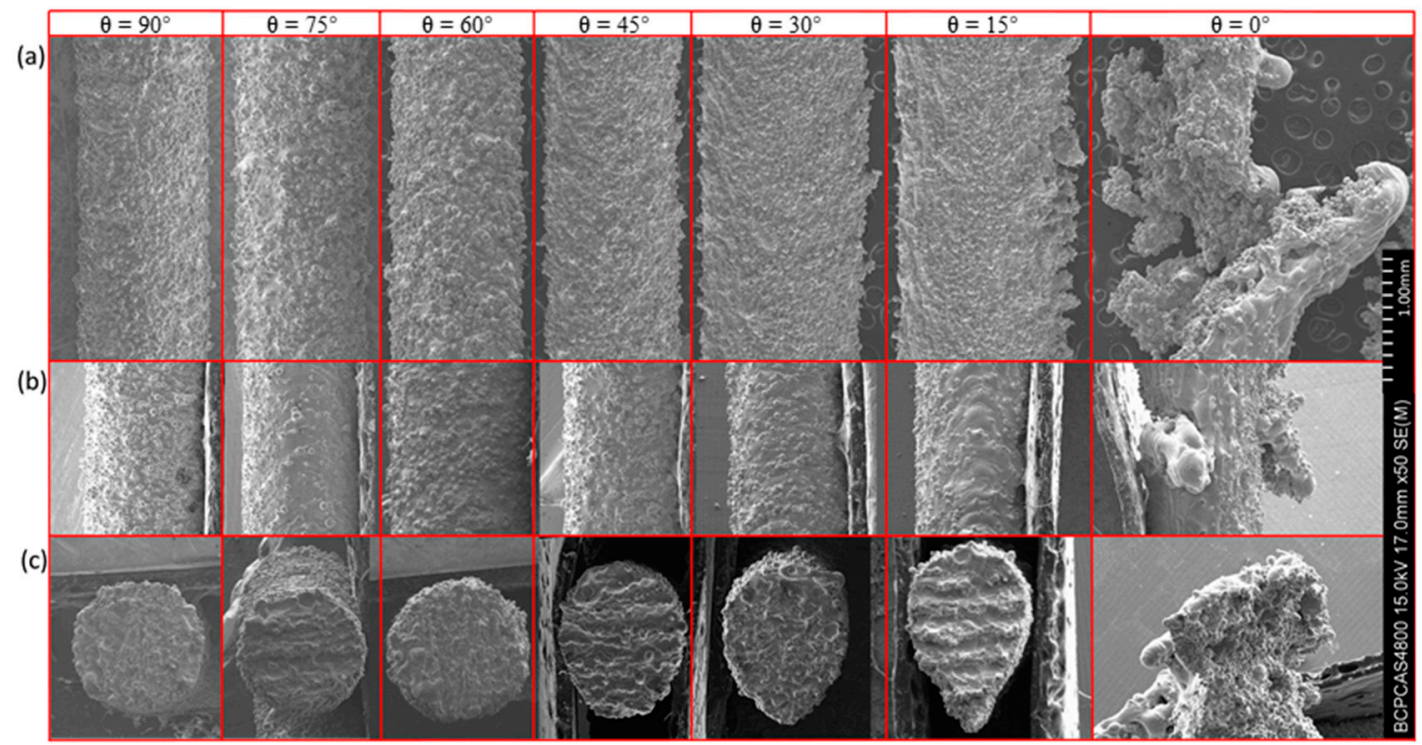

Figure 4. RA sample SEM image for design diameter of $1 \mathrm{~mm}$ and the inclination angles of $90-0^{\circ}$ in $15^{\circ}$ decrements: (a) taken from the horizontal direction; (b) taken from a vertical direction; and (c) taken from the cross section.

Figure 5 shows the SEM images of rod elements with different diameters at the same inclination angle $\left(\theta=30^{\circ}\right)$. From Figure $5 a, b$, the downward surface of the rod is rougher than the upward one, because of the preferential particle adhesion. As the diameter increased, the changes in Figure $5 a, b$, were not obvious. It indicates that the amount of metal droplets sinking is constant for the same inclination angle. However, it can be seen that with the increase of the diameter of the rod element, the shape of the cross section is close to a circle, which indicates that the shape error decreased gradually.

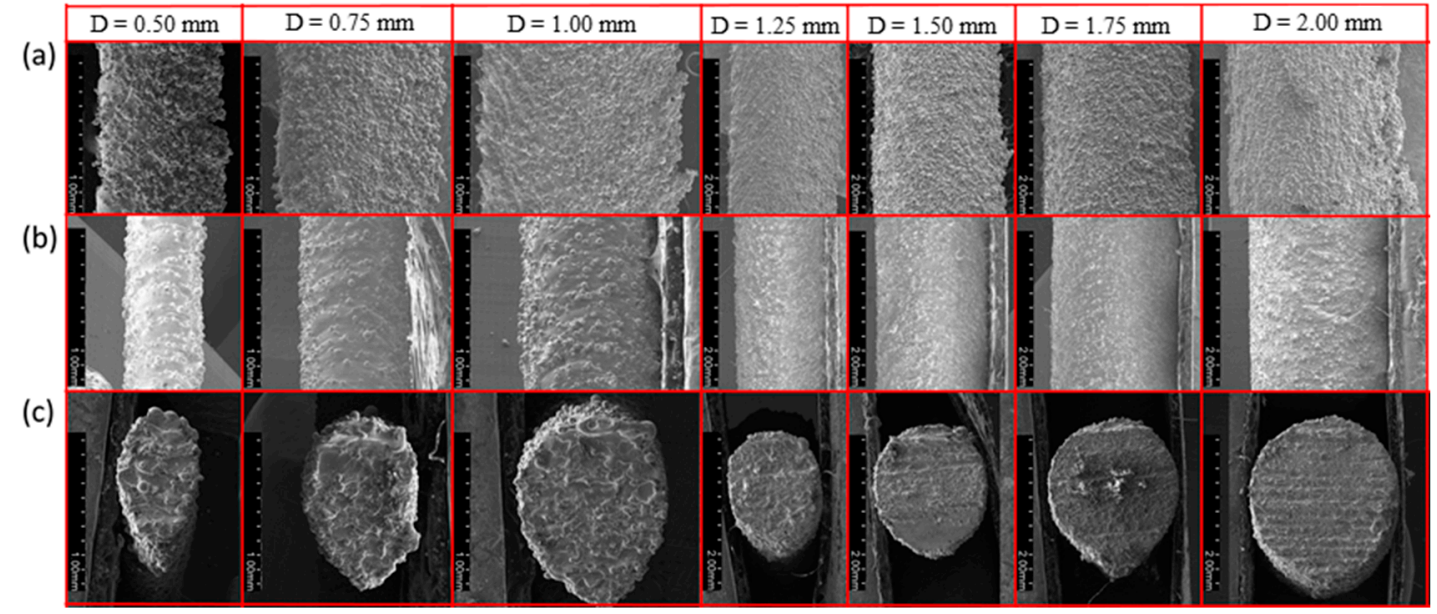

Figure 5. RA sample SEM image for inclination angles of $30^{\circ}$ and the design diameters of $0.25-2.00 \mathrm{~mm}$ in increments of $0.25 \mathrm{~mm}$ : (a) taken from the horizontal direction; (b) taken from a vertical direction; and (c) taken from the cross section.

In order to further qualify the shape error of the rod element, the lateral and longitudinal dimensions of the rod were measured. Figure 6 schematically shows the horizontal dimension $\mathrm{d} 1$ and longitudinal dimension $\mathrm{d} 2$ of the rod, along the building direction. Diameters of all the rods were measured in the direction perpendicular to their axis. For every rod unit, 10 values of the rod diameters were measured and the average value, $d$, could be readily obtained. The error was calculated as $\varepsilon=d-D$. Then, the relative error $\delta$ was evaluated as $\delta=\frac{|d-D|}{D}$, where $d$ is the measured diameter, and $D$ is the design diameter. 
The average diameter and its standard deviation are given in Table 3. The relative error is listed in Table 4. Figures 7 and 8 show the coupled effect of rod diameter and inclination angle on the shape error of the rod element.

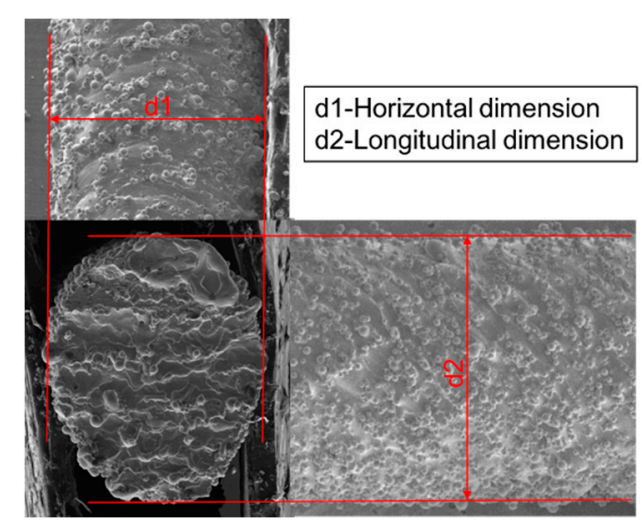

Figure 6. Schematic view of the rod diameters size measurement.

Table 3. The average diameter of the rod unit ( $\mathrm{mm}$ )and standard deviation (in the brackets).

\begin{tabular}{|c|c|c|c|c|c|c|c|c|}
\hline \multirow{2}{*}{\multicolumn{2}{|c|}{$\begin{array}{c}\text { Design Diameter } \\
D(\mathrm{~mm})\end{array}$}} & \multicolumn{7}{|c|}{ Inclination Angle $\theta\left(^{\circ}\right)$} \\
\hline & & 0 & 15 & 30 & 45 & 60 & 75 & 90 \\
\hline \multirow{4}{*}{0.50} & & 0.489 & 0.498 & 0.476 & 0.516 & 0.517 & 0.501 & 0.524 \\
\hline & d1 & $(5.284)$ & $(2.507)$ & $(0.946)$ & $(0.567)$ & $(2.565)$ & $(1.315)$ & $(1.953)$ \\
\hline & & & 0.824 & 0.822 & 0.623 & 0.561 & 0.526 & 0.515 \\
\hline & $\mathrm{d} 2$ & - & (3.055) & $(0.775)$ & $(1.431)$ & $(0.133)$ & $(0.678)$ & $(0.856)$ \\
\hline \multirow{4}{*}{0.75} & & 0.774 & 0.721 & 0.735 & 0.732 & 0.756 & 0.773 & 0.753 \\
\hline & dl & $(2.030)$ & $(0.992)$ & $(1.203)$ & $(0.451)$ & $(1.335)$ & $(1.002)$ & $(1.774)$ \\
\hline & & & 1.136 & 1.061 & 0.916 & 0.813 & 0.771 & 0.765 \\
\hline & $\mathrm{d} 2$ & - & $(2.556)$ & $(0.171)$ & $(0.509)$ & $(0.758)$ & $(1.334)$ & $(0.117)$ \\
\hline \multirow{4}{*}{1.00} & d1 & 1.014 & 0.988 & 0.960 & 0.968 & 0.956 & 0.965 & 0.984 \\
\hline & dl & $(4.524)$ & $(1.502)$ & $(0.425)$ & $(0.247)$ & $(0.623)$ & $(0.512)$ & $(0.312)$ \\
\hline & d2 & & 1.422 & 1.307 & 1.109 & 1.060 & 1.091 & 1.080 \\
\hline & $\mathrm{d} 2$ & - & $(2.007)$ & $(3.211)$ & $(1.217)$ & $(0.327)$ & $(0.376)$ & $(0.248)$ \\
\hline \multirow{4}{*}{1.25} & & 1.230 & 1.220 & 1.206 & 1.241 & 1.291 & 1.200 & 1.213 \\
\hline & d1 & $(0.134)$ & $(0.795)$ & $(0.972)$ & $(0.444)$ & (1.266) & $(0.994)$ & $(0.754)$ \\
\hline & & 1.541 & 1.636 & 1.499 & 1.326 & 1.324 & 1.316 & 1.296 \\
\hline & $\mathrm{d} 2$ & $(4.031)$ & $(6.054)$ & (1.675) & (1.136) & (1.101) & $(0.400)$ & $(0.669)$ \\
\hline \multirow{4}{*}{1.50} & & 1.470 & 1.461 & 1.549 & 1.520 & 1.489 & 1.477 & 1.544 \\
\hline & d1 & (1.011) & $(0.484)$ & $(0.645)$ & $(0.909)$ & $(2.802)$ & (1.712) & (1.599) \\
\hline & & 1.908 & 1.862 & 1.751 & 1.587 & 1.567 & 1.559 & 1.562 \\
\hline & $\mathrm{d} 2$ & $(5.124)$ & $(3.957)$ & $(4.218)$ & $(0.840)$ & $(0.383)$ & $(0.643)$ & $(0.567)$ \\
\hline \multirow{4}{*}{1.75} & & 1.738 & 1.738 & 1.750 & 1.752 & 1.720 & 1.770 & 1.689 \\
\hline & d1 & $(0.354)$ & (1.603) & $(0.827)$ & $(0.667)$ & $(0.960)$ & $(1.540)$ & (1.215) \\
\hline & d2 & 2.003 & 2.057 & 2.028 & 1.814 & 1.786 & 1.804 & 1.801 \\
\hline & $\mathrm{d} 2$ & (9.033) & $(4.892)$ & $(2.516)$ & $(0.575)$ & $(0.087)$ & (1.773) & $(0.419)$ \\
\hline \multirow{4}{*}{2.00} & d1 & 2.000 & 1.972 & 1.929 & 1.936 & 1.993 & 1.993 & 1.993 \\
\hline & al & (1.157) & $(0.213)$ & $(1.102)$ & $(1.811)$ & $(0.607)$ & $(0.802)$ & (1.558) \\
\hline & d2 & 2.425 & 2.301 & 2.256 & 2.106 & 2.080 & 2.071 & 2.066 \\
\hline & $\mathrm{d} 2$ & (7.274) & $(0.611)$ & (2.989) & $(0.837)$ & $(0.746)$ & (1.236) & $(0.179)$ \\
\hline
\end{tabular}


Table 4. The relative error of the rod unit.

\begin{tabular}{rcccccccc}
\hline \multirow{2}{*}{$\begin{array}{c}\text { Design Diameter } \\
\boldsymbol{D}(\mathbf{m m})\end{array}$} & $\mathbf{0}$ & $\mathbf{1 5}$ & $\mathbf{3 0}$ & $\mathbf{4 5}$ & $\mathbf{6 0}$ & $\mathbf{7 5}$ & $\mathbf{9 0}$ \\
\cline { 3 - 9 } 0.50 & $\mathrm{~d} 1$ & 0.022 & 0.004 & 0.048 & 0.032 & 0.034 & 0.002 & 0.048 \\
& $\mathrm{~d} 2$ & - & 0.647 & 0.645 & 0.246 & 0.121 & 0.053 & 0.030 \\
\hline \multirow{2}{*}{0.75} & $\mathrm{~d} 1$ & 0.032 & 0.038 & 0.020 & 0.024 & 0.009 & 0.031 & 0.004 \\
& $\mathrm{~d} 2$ & $\backslash$ & 0.515 & 0.416 & 0.221 & 0.084 & 0.028 & 0.020 \\
\hline \multirow{2}{*}{1.00} & $\mathrm{~d} 1$ & 0.014 & 0.0120 & 0.040 & 0.032 & 0.044 & 0.035 & 0.017 \\
& $\mathrm{~d} 2$ & - & 0.422 & 0.307 & 0.109 & 0.060 & 0.091 & 0.081 \\
\hline \multirow{2}{*}{1.25} & $\mathrm{~d} 1$ & 0.016 & 0.024 & 0.035 & 0.007 & 0.033 & 0.040 & 0.030 \\
& $\mathrm{~d} 2$ & 0.233 & 0.309 & 0.199 & 0.061 & 0.059 & 0.053 & 0.037 \\
\hline \multirow{2}{*}{1.50} & $\mathrm{~d} 1$ & 0.020 & 0.026 & 0.033 & 0.013 & 0.007 & 0.016 & 0.029 \\
& $\mathrm{~d} 2$ & 0.272 & 0.241 & 0.168 & 0.058 & 0.044 & 0.039 & 0.041 \\
\hline \multirow{2}{*}{1.75} & $\mathrm{~d} 1$ & 0.007 & 0.007 & 0.000 & 0.001 & 0.017 & 0.012 & 0.037 \\
& $\mathrm{~d} 2$ & 0.145 & 0.175 & 0.159 & 0.037 & 0.021 & 0.031 & 0.029 \\
\hline \multirow{2}{*}{2.00} & $\mathrm{~d} 1$ & 0.000 & 0.014 & 0.036 & 0.032 & 0.003 & 0.004 & 0.003 \\
& $\mathrm{~d} 2$ & 0.213 & 0.151 & 0.128 & 0.053 & 0.040 & 0.035 & 0.033 \\
\hline
\end{tabular}

(a)

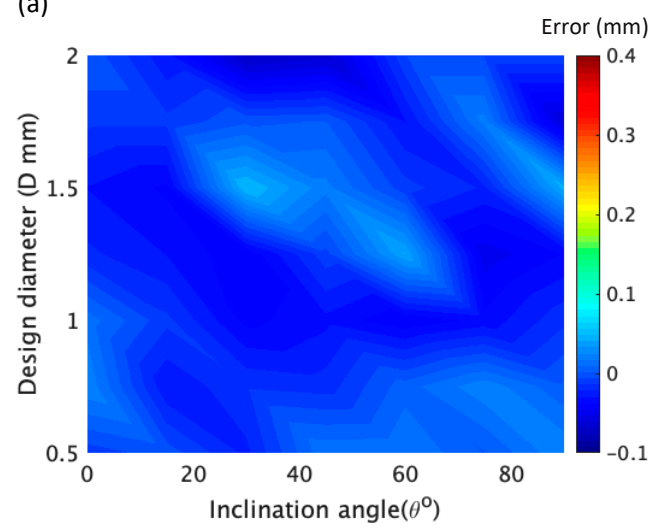

(b)

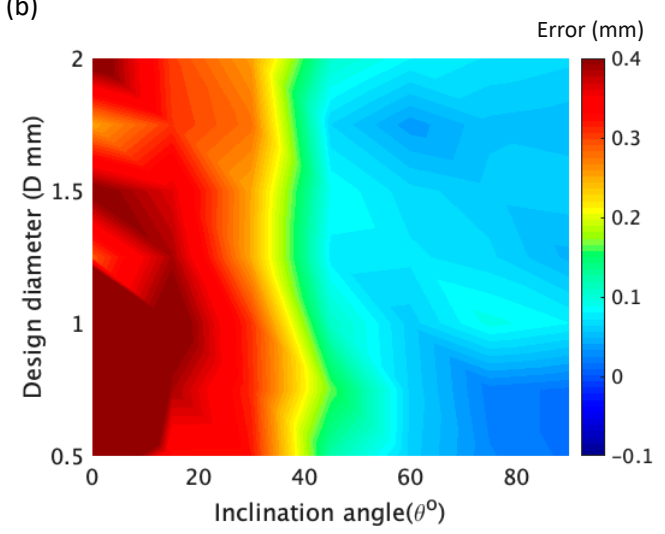

Figure 7. (a) Coupled influence of design diameter $D$ and inclination angle $\theta$ on error $\varepsilon$ of the horizontal dimension $\mathrm{d} 1$ of the rod unit. (b) Coupled influence of $D$ and $\theta$ on $\varepsilon$ of the longitudinal dimension $\mathrm{d} 2$ of the rod unit; $\mathrm{d} 1$ and $\mathrm{d} 2$ are indicated in Figure 6.
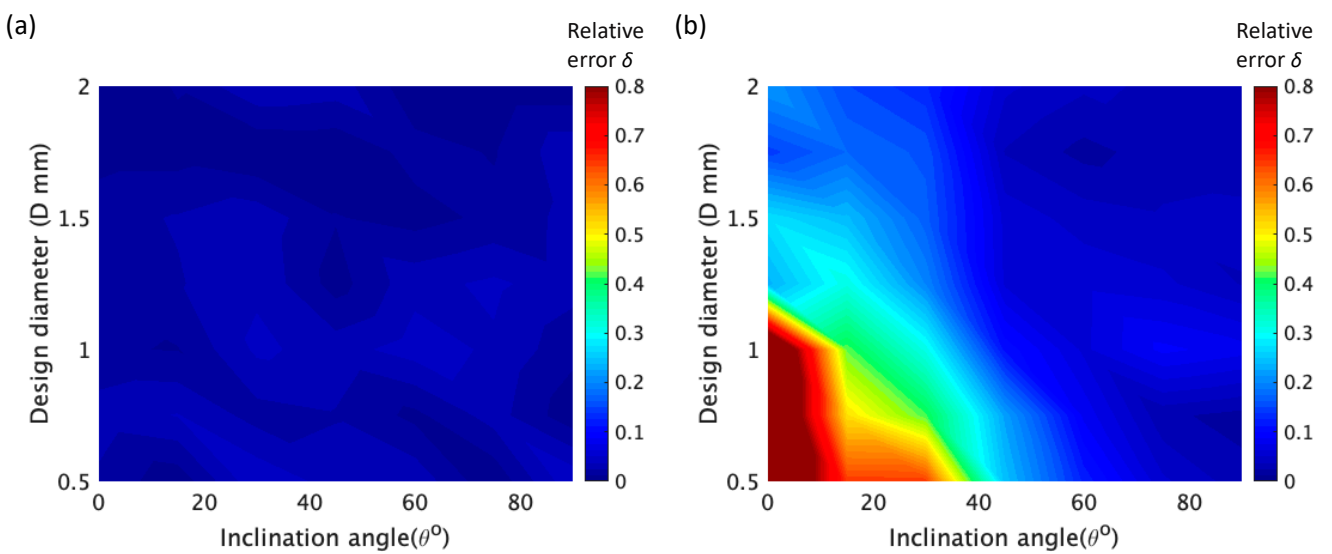

Figure 8. (a) Coupled influence of design diameter $D$ and inclination angle $\theta$ on relative error $\delta$ of the horizontal dimension $\mathrm{d} 1$ of the rod unit. (b) Coupled influence of $D$ and $\theta$ on $\delta$ of the longitudinal dimension $\mathrm{d} 2$ of the rod unit; $\mathrm{d} 1$ and $\mathrm{d} 2$ are indicated in Figure 6. 
By synthesizing these data, it can be seen that the error of the longitudinal dimension is much higher than that of the horizontal dimension. This means that the error along the bottom-to-up building direction is higher than that along the left-to-right building direction. Along the left-to-right building direction, the average relative error of the rod element was below 0.05 , according to Figure 8a. However, along the bottom-to-up building direction, the error become acceptable (smaller than $0.1 \mathrm{~mm}$ ) only when the inclination angle was higher than $45^{\circ}$, which is insensitive to the design diameter, as shown in Figure $7 \mathrm{~b}$. With the increase of the design diameter, the relative error decreased (see Figure 8b).

How should we understand such shape error? Since there is only powder support in the first few layers of the fabricated rod, the laser melts more powder under the bottom layer which eventually adheres to the rod. Moreover, due to the instability of the powder support, the melted metal droplets will subside. The depression will fill with more powder with the ongoing process of the spreading powder. Both of the processes above can increase the rod diameter along the bottom-to-up building direction. With the increase of the inclination angle, these effects are gradually reduced and the error decreases. Since the degree of laser melting and the degree of metal droplet subsidence are fixed, it does not change with changes of rod diameter. Thus, when the rod diameter is increased, the relative error is reduced.

\subsection{Tensile Test of RB Samples}

To explore the anisotropic mechanical properties of the rod units, the RB samples with partial support were designed and manufactured. The fabricated RB samples are shown in Figure 3b. Necessary support was added when printing in order to ensure consistent cross-sectional area of the samples for tensile tests. The rod unit diameter was found to be almost uniform, which can be seen to some extend from Figure 3b. All of the samples were cut into individual tensile specimens by electrical discharge machining. The stressstrain curves of the rod elements at different inclination angles when the design diameter was $1.75 \mathrm{~mm}$ are shown in Figure 9. As we can see, the little influence has reflected the inclination angle of rod on mechanical properties. This weak influence of inclination angle is also observed for rod elements with other diameters. The stress-strain curves of the rod elements with different diameters, and the inclination angle the same as $0^{\circ}$ are shown in Figure 10. It can be seen that the tensile strength exhibits weak size effect. Namely, the smaller the diameter the higher the tensile strength. Such week size dependence is only observed when the inclination angle is smaller than about $20^{\circ}$, as shown in Figure $11 \mathrm{~b}$. The change of the tensile strength is not significant. On the other hand, Figure 10b shows that the elongation increases with the increase of the rod diameter. This is expected since a smaller diameter corresponds to larger aspect ratios of the rod unit. Actually, the different slopes of elongation are caused by the different equivalent modulus with the rod diameter changed. Figure 12 shows the schematic diagram of the tensile sample. The $D$ is the diameter of the rod, and $l_{2}$ is the rod's length. $l_{1}$ is the plate length, $s$ is the plate width, and the thickness is equal to $D$. The stretching force is $\boldsymbol{F}$. Combined with Equations (1)-(3), the equivalent modulus $E_{e}$ can be determined as Equation (4). $\Delta l$ is the stretched length, $\varepsilon_{e}$ is the equivalent strain, $\sigma_{e}$ is the equivalent stress, and $E$ is the Young's modulus. As we can see in Equation (4), as the diameter increases, the equivalent modulus will decrease. Table 5 summarizes the tensile strength of each rod and is shown in Figure 11. The tensile strength of all rods is about $1100 \mathrm{MPa}$. It can be concluded that the diameter and inclination angle have no significant impacts on the mechanical properties of the rod. The smaller rod with lower inclination angle exhibits a little higher tensile strength.

$$
\begin{gathered}
\Delta l=\frac{F}{(D s) E} l_{1} \times 2+\frac{F}{\frac{1}{4} \pi D^{2} E} l_{2} \\
\varepsilon_{e}=\frac{\Delta l}{l_{2}}
\end{gathered}
$$




$$
\begin{gathered}
\sigma_{e}=\frac{F}{\frac{1}{4} \pi D^{2}} \\
E_{e}=\frac{\sigma_{e}}{\varepsilon_{e}}=\frac{E}{\frac{\pi D l_{1}}{2 s l_{2}}+1}
\end{gathered}
$$

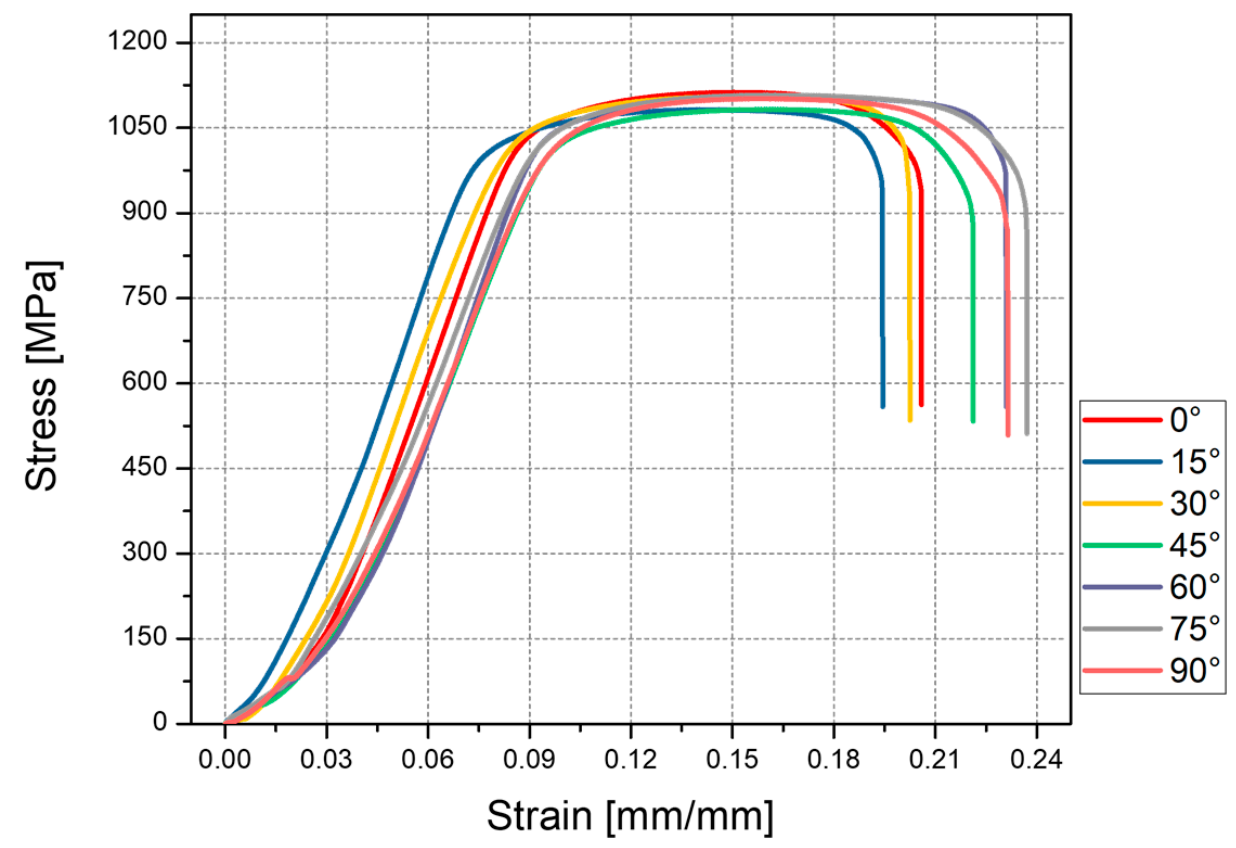

Figure 9. Stress-strain response of the RB sample with diameter of $1.75 \mathrm{~mm}$.

(a)

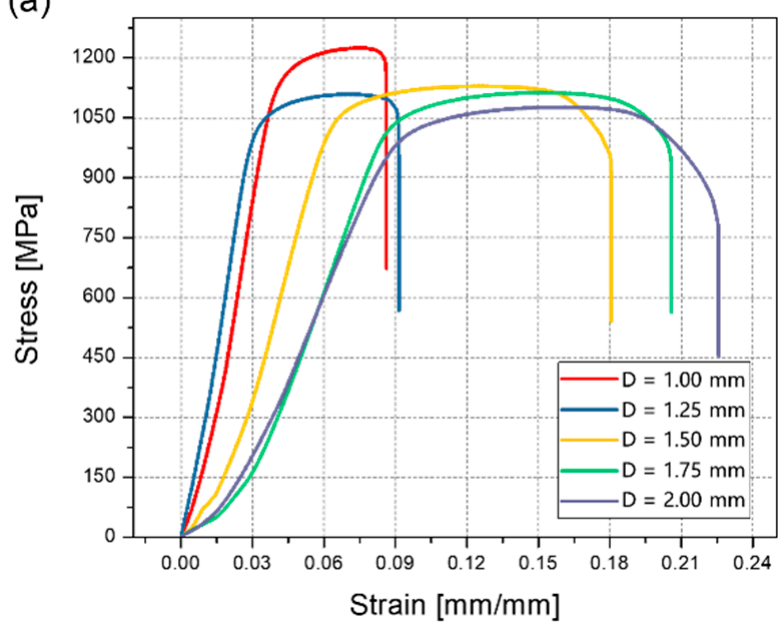

(b)

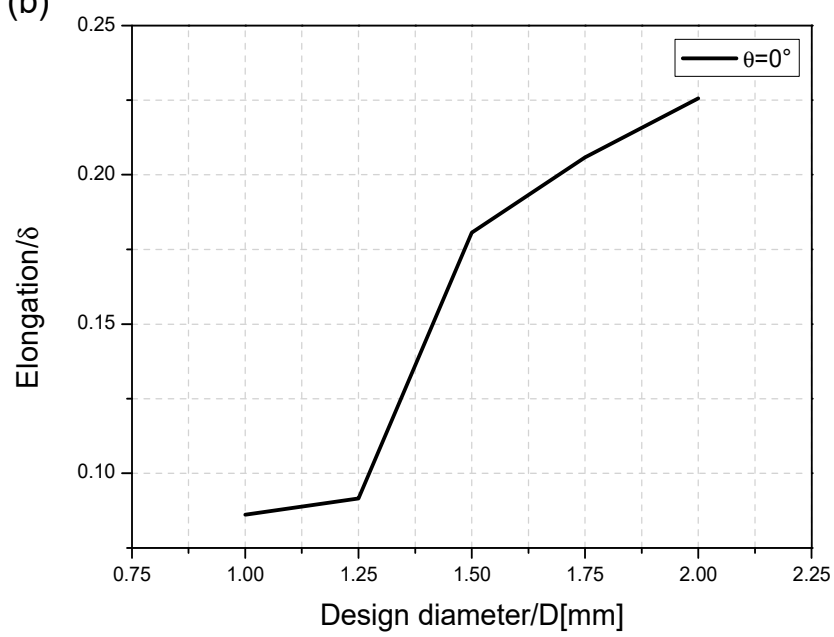

Figure 10. (a) Stress-strain response of the RB sample with inclination angle of $0^{\circ}$. (b) Elongation-Design diameter response of the RB sample with inclination angle of $0^{\circ}$. 
(a)

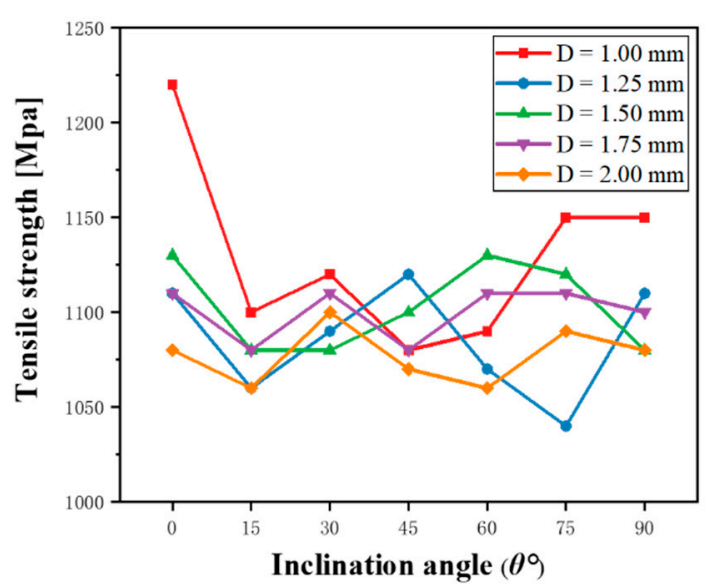

(b)

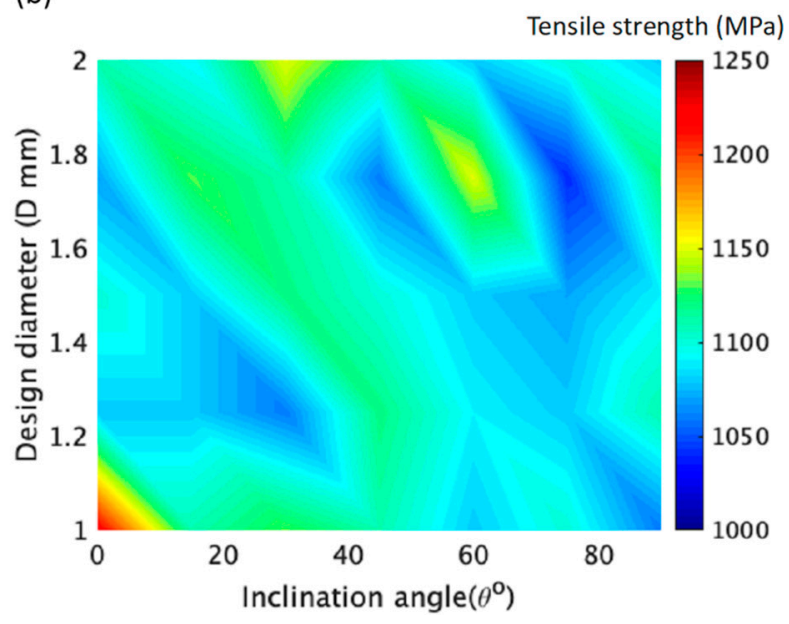

Figure 11. (a) Tensile strength-inclination angle curves with different diameter. (b) Coupled influence of the inclination angle $\theta$ and design diameter $D$ on the tensile strength of rod unit.

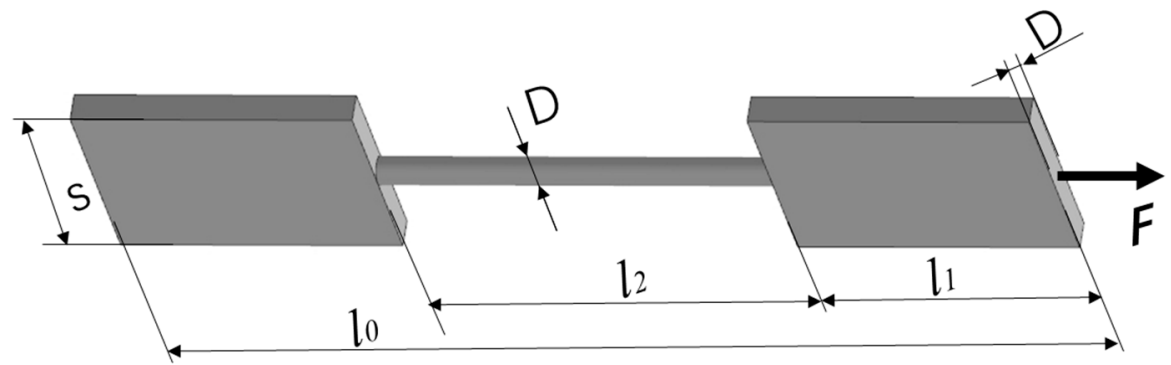

Figure 12. Schematic diagram of the tensile sample.

Table 5. Tensile strength of RB sample (MPa).

\begin{tabular}{cccccc}
\hline \multirow{2}{*}{$\begin{array}{c}\text { Inclination Angle } \\
\boldsymbol{\theta}\left({ }^{\circ}\right)\end{array}$} & $\mathbf{1 . 0 0}$ & $\mathbf{1 . 2 5}$ & $\mathbf{1 . 5 0}$ & $\mathbf{1 . 7 5}$ & $\mathbf{2 . 0 0}$ \\
\cline { 2 - 5 } & 1220 & 1110 & 1130 & 1110 & 1080 \\
0 & 1100 & 1060 & 1080 & 1080 & 1060 \\
15 & 1120 & 1090 & 1080 & 1110 & 1100 \\
30 & 1080 & 1120 & 1100 & 1080 & 1070 \\
45 & 1090 & 1070 & 1130 & 1110 & 1060 \\
60 & 1150 & 1040 & 1120 & 1110 & 1090 \\
75 & 1150 & 1110 & 1080 & 1100 & 1080 \\
90 & & & & &
\end{tabular}

The mechanical property of Ti- $6 \mathrm{Al}-4 \mathrm{~V}$ is directly determined by the lamellar $\alpha \mathrm{mi}-$ crostructure, the $\beta$ grain orientation, and the $\beta$ grain size [38-40]. In the SLM fabricating component, the different orientation of the $\beta$ grain is the key to influencing the anisotropy of mechanical properties [40]. It leads to a small size of the $\beta$ grains and the lamellar $\alpha$ microstructure for tiny molten pool and high cooling rate in the small rod elements of lattice structures. The tensile strength of the rod unit is up to $1100 \mathrm{MPa}$, which is close to the data reported before [31]. The effect of grain orientation is relatively weak. Therefore, there is no obvious anisotropy of the mechanical properties in the tensile test. It is good news for designers that the anisotropy of the tensile strength can be ignored when designing lattice structures for the considered ranges.

\subsection{Error Fitting and Area Calculation}

The previous section indicates that the SLM process has no obvious influence on the mechanical properties of the rod element if uniform cross-section is used. Thus, the 
cross-sectional area is the main factor which affects the load capacity of the rod element. To better guide the lattice structure design, it will be great to obtain the relation between the cross-sectional area and the inclination angle. At first, nonlinear fitting of the longitudinal error is carried out and the Boltzmann function [41] can be fitted well. The formula is as follows:

$$
\varepsilon(\theta)=0.050+\frac{0.33}{1+e^{\frac{\theta-34}{6.1}}}
$$

where $\varepsilon(\theta)$ refers to the longitudinal error when the inclination angle is $\theta$. The R-Square (COD) is 0.93 and the Adj. R-Square is 0.92 . Figure 13 shows the comparison of longitudinal error between Boltzmann curve fitting and the actual rod unit. It can be seen that actual values agree very well with the fitted values.

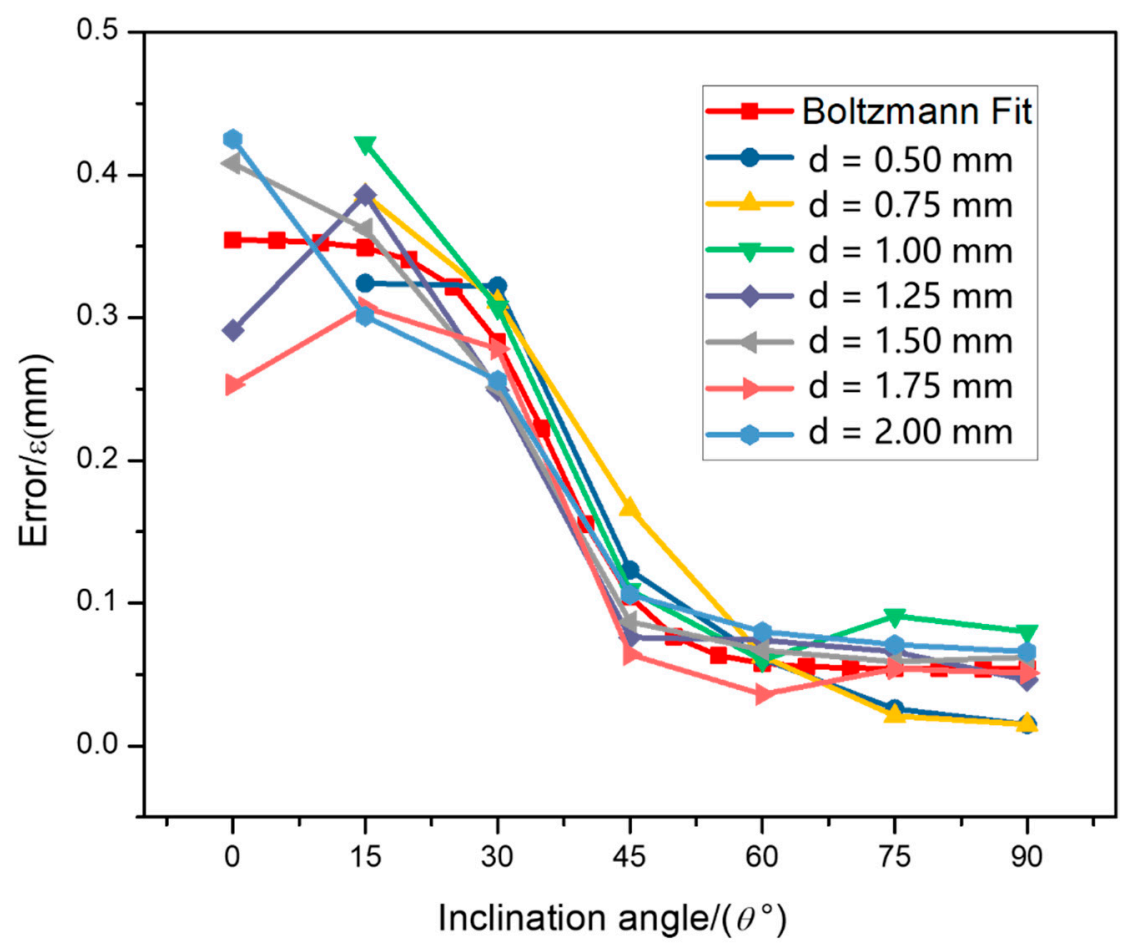

Figure 13. Comparison of longitudinal error between Boltzmann curve fitting and actual rod unit.

Moreover, the cross-sectional area can be approximated by the diameter $D$ and longitudinal error $\varepsilon$. The cross section of the rod can be seen surrounded by a circle and a parabola (Figure 14a). It can be approximated using a model of Figure 14b. The parabola is tangent to the circle and its vertex is $\varepsilon$ from the bottom of the circle. The cross-sectional area can be determined as:

$$
\begin{gathered}
A=\frac{4}{3} \sqrt{r^{2}-\frac{1}{4 a^{2}}}\left(b-\frac{1}{2 a}\right)+r^{2}\left(\pi-\cos ^{-1}\left(\frac{1}{2 a r}\right)\right)+\frac{1}{2 a} \sqrt{r^{2}-\frac{1}{4 a^{2}}} \\
a=\frac{\sqrt{b^{2}-r^{2}}+b}{2 r^{2}} \\
b=r+\varepsilon
\end{gathered}
$$

where $A$ is the cross-sectional area, $\varepsilon$ is the longitudinal error, and $r$ is the radius of the rod. The cross-sectional area of the rod can be calculated from the diameter and inclination angle, in conjunction with Equations (5)-(8). In order to verify the accuracy of the formula, the cross-sectional area was measured by taking a rod unit from each of the RA samples and comparing it with the calculated cross-sectional area (Figure 15). The solid line in the 
figure represents the measured value and the dotted line represents the calculated value. It can be seen that the measured value and the calculated value are very close.
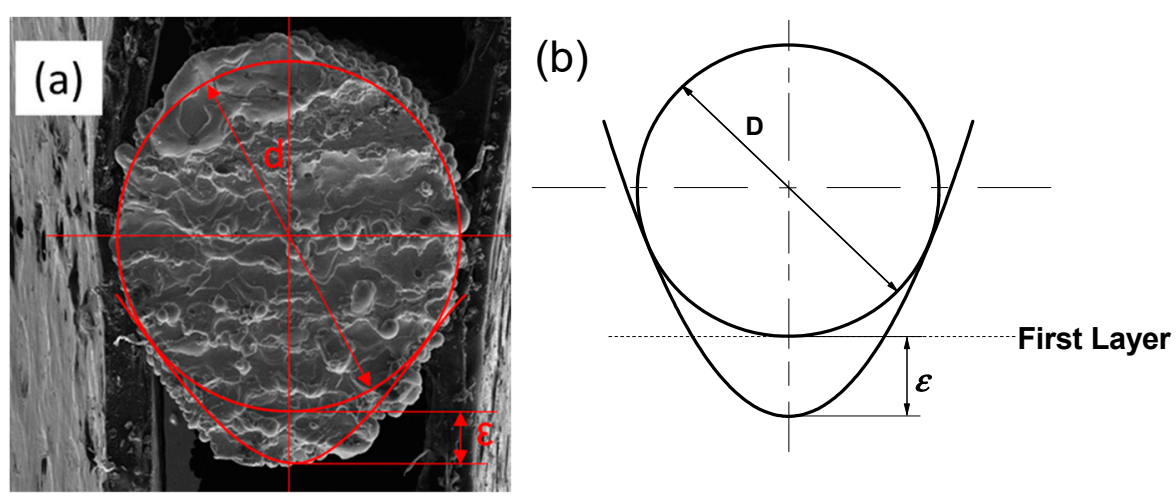

Figure 14. (a) Cross section of rod unit. (b) Geometric model of cross section.

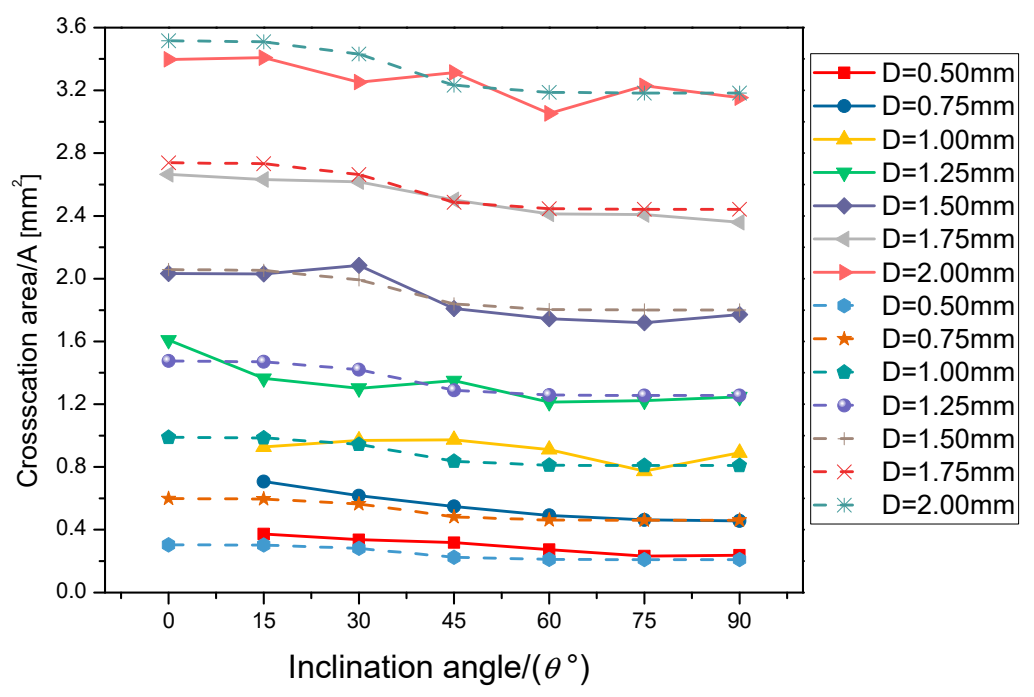

Figure 15. Comparison of measured values and calculated values. Solid line represents the measured value and dash line represents calculated value.

\section{Conclusions}

To guide the optimal design of lattice structures, a clear relation between the design parameter and the performance of the rod units of the lattice structure must be obtained. In this work, the coupling effects of the two most widely-used design parameters (i.e., the inclination angle and feature diameter) were systematically studied. Two groups of samples were fabricated using SLM, both with and without support. Through morphological observation and mechanical testing, the following conclusions were obtained:

(1) When fabricating lattice structures using SLM, there is generally no support because it is difficult to remove when constrained by limited access. In the case of there being no support, the inclination angle has a significant influence on the forming quality of the rod. With the increase of the inclination angle, the morphological error of the rod element is gradually reduced. When the inclination angle is below $30^{\circ}$, the error along the bottom-to-up direction is large (more than $0.2 \mathrm{~mm}$ ). The error decreases rapidly when the inclination angle is $45^{\circ}$. The diameter of the rod has little effect on the profile error. However, with the increase of design diameter, the relative error decreases gradually.

(2) To fabricate tensile test samples, some additional support was used during SLM fabrication. The rod unit exhibited good mechanical properties and the tensile strength 
was up to $1100 \mathrm{MPa}$. The inclination angle and the diameter of the rod element have a limited influence on the mechanical properties of the rod, which implies that it is reasonable to use isotropic tensile strength value when designing the lattice structure.

(3) The error fitting formula and cross-sectional area calculation formula of the rod units were proposed. The former can determine the longitudinal error according to the inclination angle. The later can estimate the cross-sectional area of rod unit after fabrication.

(4) In summary, this study shows that the inclination of rod element has a great influence on the shape of the rod, while the mechanical properties of the rod are not anisotropic due to the angle change. The formulas proposed in Section 3.3 can be used to predict the cross-sectional area of rod element after fabrication. The load capacity of the rod can be estimated accordingly, which provides a reference for lattice structure design.

\begin{abstract}
Author Contributions: Conceptualization, C.J.; methodology, C.L. and J.L.; validation, Y.Z.; formal analysis, Y.Z. and F.W.; investigation, C.J. and J.W.; resources, Y.Z., J.W. and C.L.; data curation, Y.Z. and F.W.; writing — original draft preparation, C.J.; writing—review and editing, C.J.; visualization, Y.Z. and J.L.; supervision, J.L.; project administration, J.W. and F.W.; funding acquisition, C.L. All authors have read and agreed to the published version of the manuscript.
\end{abstract}

Funding: The work was funded by the National Natural Science Foundation of China (51875041).

Institutional Review Board Statement: Not applicable.

Informed Consent Statement: Not applicable.

Data Availability Statement: Data sharing is not applicable to this article.

Conflicts of Interest: The authors declare no conflict of interest.

\title{
References
}

1. Alsalla, H.; Hao, L.; Smith, C. Fracture toughness and tensile strength of 316L stainless steel cellular lattice structures manufactured using the selective laser melting technique. Mater. Sci. Eng. A 2016, 669, 1-6. [CrossRef]

2. Beyer, C.; Figueroa, D. Design and Analysis of Lattice Structures for Additive Manufacturing. J. Manuf. Sci. Eng. 2016, 138, 121014. [CrossRef]

3. Červinek, O.; Werner, B.; Koutný, D.; Vaverka, O.; Pantělejev, L.; Paloušek, D. Computational Approaches of Quasi-Static Compression Loading of SS316L Lattice Structures Made by Selective Laser Melting. Materials 2021, 14, 2462. [CrossRef]

4. Wang, X.; Wang, C.; Zhou, X.; Wang, D.; Zhang, M.; Gao, Y.; Wang, L.; Zhang, P. Evaluating Lattice Mechanical Properties for Lightweight Heat-Resistant Load-Bearing Structure Design. Materials 2020, 13, 4786. [CrossRef]

5. Yan, C.; Hao, L.; Hussein, A.; Young, P.; Raymont, D. Advanced lightweight 316L stainless steel cellular lattice structures fabricated via selective laser melting. Mater. Des. 2014, 55, 533-541. [CrossRef]

6. Nakajima, H. Fabrication, properties and application of porous metals with directional pores. Prog. Mater. Sci. 2007, 52, 1091-1173. [CrossRef]

7. Evans, A.G.; Hutchinson, J.W.; Fleck, N.A.; Ashby, M.F.; Wadley, H.N.G. The topological design of multifunctional cellular metals. Prog. Mater. Sci. 2001, 46, 309-327. [CrossRef]

8. Moon, S.K.; Tan, Y.E.; Hwang, J.; Yoon, Y.J. Application of 3D printing technology for designing light-weight unmanned aerial vehicle wing structures. Int. J. Precis. Eng. Manuf. Green Technol. 2014, 1, 223-228. [CrossRef]

9. Kuschmitz, S.; Ring, T.P.; Watschke, H.; Langer, S.C.; Vietor, T. Design and additive manufacturing of porous sound absorbers-A machine-learning approach. Materials 2021, 14, 1747. [CrossRef] [PubMed]

10. Rahman, H.; Yarali, E.; Zolfagharian, A.; Serjouei, A.; Bodaghi, M. Energy absorption and mechanical performance of functionally graded soft-hard lattice structures. Materials 2021, 14, 1366. [CrossRef] [PubMed]

11. Wang, J.; Evans, A.G. On the performance of truss panels with Kagome cores. Int. J. Solids Struct. 2003, 40, 6981-6988. [CrossRef]

12. Kooistra, G.W.; Wadley, H.N.G. Lattice truss structures from expanded metal sheet. Mater. Des. 2007, 28, 507-514. [CrossRef]

13. Queheillalt, D.T.; Wadley, H.N.G. Cellular metal lattices with hollow trusses. Acta Mater. 2005, 53, 303-313. [CrossRef]

14. Wadley, H.N.G.; Fleck, N.A.; Evans, A.G. Fabrication and structural performance of periodic cellular metal sandwich structures. Compos. Sci. Technol. 2003, 63, 2331-2343. [CrossRef]

15. Li, P.; Wang, Z.; Petrinic, N.; Siviour, C.R. Deformation behaviour of stainless steel microlattice structures by selective laser melting. Mater. Sci. Eng. A 2014, 614, 116-121. [CrossRef]

16. Rashed, M.G.; Ashraf, M.; Mines, R.A.W.; Hazell, P.J. Metallic microlattice materials: A current state of the art on manufacturing, mechanical properties and applications. Mater. Des. 2016, 95, 518-533. [CrossRef] 
17. Sing, S.L.; An, J.; Yeong, W.Y.; Wiria, F.E. Laser and electron-beam powder-bed additive manufacturing of metallic implants: A review on processes, materials and designs. J. Orthop. Res. 2016, 34, 369-385. [CrossRef] [PubMed]

18. Shi, X.; Ma, S.; Liu, C.; Wu, Q. Parameter optimization for Ti-47Al-2Cr-2Nb in selective laser melting based on geometric characteristics of single scan tracks. Opt. Laser Technol. 2017, 90, 71-79. [CrossRef]

19. de Jesus, J.; Ferreira, J.A.M.; Borrego, L.; Costa, J.D.; Capela, C. Fatigue failure from inner surfaces of additive manufactured ti-6al-4v components. Materials 2021, 14, 737. [CrossRef] [PubMed]

20. Sing, S.L.; Yeong, W.Y.; Wiria, F.E. Selective laser melting of titanium alloy with $50 \mathrm{wt} \%$ tantalum: Microstructure and mechanical properties. J. Alloys Compd. 2016, 660, 461-470. [CrossRef]

21. Loh, L.E.E.; Liu, Z.H.H.; Zhang, D.Q.Q.; Mapar, M.; Sing, S.L.L.; Chua, C.K.K.; Yeong, W.Y.Y. Selective laser melting of aluminium alloy using a uniform beam profile. Virtual Phys. Prototyp. 2014, 9, 11-16. [CrossRef]

22. Casalino, G.; Campanelli, S.L.; Contuzzi, N.; Ludovico, A.D. Experimental investigation and statistical optimisation of the selective laser melting process of a maraging steel. Opt. Laser Technol. 2015, 65, 151-158. [CrossRef]

23. Yasa, E.; Deckers, J.; Kruth, J.-P.; Rombouts, M.; Luyten, J. Charpy impact testing of metallic selective laser melting parts. Virtual Phys. Prototyp. 2010, 5, 89-98. [CrossRef]

24. Cloots, M.; Kunze, K.; Uggowitzer, P.J.; Wegener, K. Microstructural characteristics of the nickel-based alloy IN738LC and the cobalt-based alloy Mar-M509 produced by selective laser melting. Mater. Sci. Eng. A 2016, 658, 68-76. [CrossRef]

25. Arabnejad, S.; Burnett Johnston, R.; Pura, J.A.; Singh, B.; Tanzer, M.; Pasini, D. High-strength porous biomaterials for bone replacement: A strategy to assess the interplay between cell morphology, mechanical properties, bone ingrowth and manufacturing constraints. Acta Biomater. 2016, 30, 345-356. [CrossRef] [PubMed]

26. Yan, C.; Hao, L.; Hussein, A.; Raymont, D. Evaluations of cellular lattice structures manufactured using selective laser melting. Int. J. Mach. Tools Manuf. 2012, 62, 32-38. [CrossRef]

27. Al-Saedi, D.S.J.; Masood, S.H.; Faizan-Ur-Rab, M.; Alomarah, A.; Ponnusamy, P. Mechanical properties and energy absorption capability of functionally graded F2BCC lattice fabricated by SLM. Mater. Des. 2018, 144, 32-44. [CrossRef]

28. Mazur, M.; Leary, M.; McMillan, M.; Sun, S.; Shidid, D.; Brandt, M. 5-Mechanical Properties of Ti6Al4V and AlSi12Mg Lattice Structures Manufactured by Selective Laser Melting (SLM); Elsevier Ltd.: Amsterdam, The Netherlands, 2017; ISBN 9780081004333

29. Thijs, L.; Verhaeghe, F.; Craeghs, T.; Van Humbeeck, J.; Kruth, J.P. A study of the microstructural evolution during selective laser melting of Ti-6Al-4V. Acta Mater. 2010, 58, 3303-3312. [CrossRef]

30. Chen, L.Y.; Huang, J.C.; Lin, C.H.; Pan, C.T.; Chen, S.Y.; Yang, T.L.; Lin, D.Y.; Lin, H.K.; Jang, J.S.C. Anisotropic response of Ti-6Al-4V alloy fabricated by 3D printing selective laser melting. Mater. Sci. Eng. A 2017, 682, 389-395. [CrossRef]

31. Facchini, L.; Magalini, E.; Robotti, P.; Molinari, A.; Höges, S.; Wissenbach, K. Ductility of a Ti-6Al-4V alloy produced by selective laser melting of prealloyed powders. Rapid Prototyp. J. 2010, 16, 450-459. [CrossRef]

32. Leary, M.; Mazur, M.; Elambasseril, J.; McMillan, M.; Chirent, T.; Sun, Y.; Qian, M.; Easton, M.; Brandt, M. Selective laser melting (SLM) of AlSi12Mg lattice structures. Mater. Des. 2016, 98, 344-357. [CrossRef]

33. Kadirgama, K.; Harun, W.S.W.; Tarlochan, F.; Samykano, M.; Ramasamy, D.; Azir, M.Z.; Mehboob, H. Statistical and optimize of lattice structures with selective laser melting (SLM) of Ti6AL4V material. Int. J. Adv. Manuf. Technol. 2018, 97, 495-510. [CrossRef]

34. Boyer, R.R. An overview on the use of titanium in the aerospace industry. Mater. Sci. Eng. A 1996, 213, 103-114. [CrossRef]

35. Zhang, S.; Wei, Q.; Cheng, L.; Li, S.; Shi, Y. Effects of scan line spacing on pore characteristics and mechanical properties of porous Ti6Al4V implants fabricated by selective laser melting. Mater. Des. 2014, 63, 185-193. [CrossRef]

36. Elias, C.N.; Meyers, M.A.; Valiev, R.Z.; Monteiro, S.N. Ultrafine grained titanium for biomedical applications: An overview of performance. J. Mater. Res. Technol. 2013, 2, 340-350. [CrossRef]

37. ASTM International. Standard Test Methods for Tension Testing of Metallic Materials. In ASTM Book of Standards; ASTM International: West Conshohocken, PA, USA, 2015; pp. 1-27. [CrossRef]

38. Jia, W.; Ma, L.; Tang, Y.; Le, Q.; Fu, L. Relationship between microstructure and properties during multi-pass, variable routes and different initial temperatures hot flat rolling of AZ31B magnesium alloy. Mater. Des. 2016, 103, 171-182. [CrossRef]

39. Zhu, Y.Z.; Wang, S.Z.; Li, B.L.; Yin, Z.M.; Wan, Q.; Liu, P. Grain growth and microstructure evolution based mechanical property predicted by a modified Hall-Petch equation in hot worked Ni76Cr19AlTiCo alloy. Mater. Des. 2014, 55, 456-462. [CrossRef]

40. Shi, X.; Ma, S.; Liu, C.; Wu, Q.; Lu, J.; Liu, Y.; Shi, W. Selective laser melting-wire arc additive manufacturing hybrid fabrication of Ti-6Al-4V alloy: Microstructure and mechanical properties. Mater. Sci. Eng. A 2017, 684, 196-204. [CrossRef]

41. Navarro-Verdugo, A.L.; Goycoolea, F.M.; Romero-Meléndez, G.; Higuera-Ciapara, I.; Argüelles-Monal, W. A modified Boltzmann sigmoidal model for the phase transition of smart gels. Soft Matter 2011, 7, 5847-5853. [CrossRef] 